\title{
Progesterone regulates hypothalamic-pituitary-thyroid axis
}

\author{
Chunyun Zhong, Kewen Xiong, Xin Wang \\ Department of Environmental Toxicity, Third Hospital of Shanxi University
}

Keywords: Progestin; Progesterone; hypothalamic-pituitary-thyroid axis

\begin{abstract}
Progesterone is a natural steroid hormone excreted by animals and humans, which has been frequently detected in the aquatic ecosystems. The effects of the residual progesterone on fish are unclear. In this study, we aimed to examine the effects of progesterone on the hypothalamic-pituitary-thyroid (HPT) axis by detecting the gene transcriptional expression levels. Zebrafish embryos were treated with different concentrations of progesterone from 12 hours postfertilization (hpf) to $120 \mathrm{hpf}$. Total mRNA was extracted and the transcriptional profiles of genes involved in HPT axis were examined using qPCR. The genes related to thyroid hormone metabolism and thyroid hormone synthesis were upregulated in zebrafish exposed to progesterone. These results indicated that progesterone affected the mRNA expression of genes involved in the HPT axis, which might interrupt the endocrine system in zebrafish. Our data also suggested that zebrafish is a useful tool for evaluating the effects of chemicals on the thyroid endocrine system.
\end{abstract}

\section{Introduction}


Natural and synthetic steroid hormones are active endocrine disrupters, which have been detected in the aquatic systems [1-5]. These endocrine disrupters have the potential effects on the fish reproductive system at very low concentration, such as environmental levels [6-9]. Progesterone is a steroid hormone that impairs the reproduction in animals and humans [10-12]. Previous studies report that progesterone can affect the meiotic oocyte maturation in human, mammals and female fish [13-18].

Low levels of progesterone and its metabolites, which are originally excreted by human and mammals, have been detected in the aquatic ecosystems including surface water and rivers [19-25].

Thyroid hormones play an essential role in the maintenance of tissues and biological functions in vertebrates [26-31]. In fish, the HPT axis regulates the thyroid endocrine system by modulating their homeostasis [32-35]. In this study, we investigated the effects of progesterone on the transcriptional profiles of genes involved in HPT axis of zebrafish. Our results confirmed that progesterone can cause disruption to the thyroid system by impairing the endocrine homeostasis.

\section{Materials and methods}

\section{Chemicals}

Progesterone was purchased from Sigma-Aldrich (Cat NO. P0130-25G) and dissolved in dimethyl sulfoxide to make the stock solution. 


\section{Zebrafish maintenance and drug treatment}

Wild type AB line zebrafish were raised and kept under standard laboratory conditions at $28 \pm 0.5^{\circ} \mathrm{C}$. Adult fish were naturally crossed and normally developed embryos were collected. Embryos were randomly divided into each

group containing different concentrations of progesterone $(0,1,10,100$ and 1000 $\mathrm{ng} / \mathrm{L})$. The eggs were treated with progesterone from 12 hours post-fertilization (hpf) to $120 \mathrm{hpf}$. Water was changed twice per day and exposed-eggs were collected for mRNA analysis at 5 days post-fertilization (dpf). Control group was treated with $0.05 \%$ DMSO.

\section{Quantitative real-time PCR (qPCR)}

Quantitative real-time PCR was performed as described somewhere else [36]. Fifty zebrafish larvae per group were collected and homogenized, total RNA was extracted using Direct-zol ${ }^{\mathrm{TM}}$ RNA MiniPrep Kit (Zymo Research) following manufacturer's protocol. First-strand cDNA was synthesized using SuperScript III First-Strand Synthesis System (Thermo Fisher Scientific). The qPCR was performed using SYBR Green Real-Time PCR Master Mixes (Thermo Fisher Scentific) and analyzed on a QuantStudio ${ }^{\mathrm{TM}} 6$ Flex Real-Time PCR System. The primer sequences of target genes were listed somewhere else. The amplification protocol was as follows: denaturation at $95^{\circ} \mathrm{C}$ for $15 \mathrm{~min}$, followed by 40 cycles of $95^{\circ} \mathrm{C}$ for $10 \mathrm{~s}, 60^{\circ} \mathrm{C}$ for $60 \mathrm{~s}$.

\section{Statistical analysis}


The normality and homogeneity of variance were tested using Kolmogorov-

Smirnov and Levene's tests, respectively. Differences between the control and drug-treated groups were evaluated by on-way analysis of variance (ANOVA), followed by Tukey's test. $\mathrm{P}<0.05$ was considered statistically significant.

\section{Results}

In order to investigate the effect of progesterone on the mRNA expression of genes involved in HPT axis of zebrafish, embryos were exposed to different concentrations of progesterone $(0,1,10,100$ and $1000 \mathrm{ng} / \mathrm{L})$, and mRNA expression profiles were examined at $5 \mathrm{dpf}$. Treated with $100 \mathrm{ng} / \mathrm{L}$ progesterone significantly increased the gene expression of sodium/iodide symporter (slc5a5) and thyroid-stimulating hormone beta $(\operatorname{tsh} \beta)$. The gene expression involved in the HPT axis had no significant changes in the 1 and $10 \mathrm{ng} / \mathrm{L}$ progesterone-treated groups. Treatment with higher concentrations (1000 ng/L) significantly induced the expression of NK2 homeobox 1a (nkx2.1), paired box protein 8 (pax8) and uridinediphosphate glucuronosyltransferase (ugt1ab). 


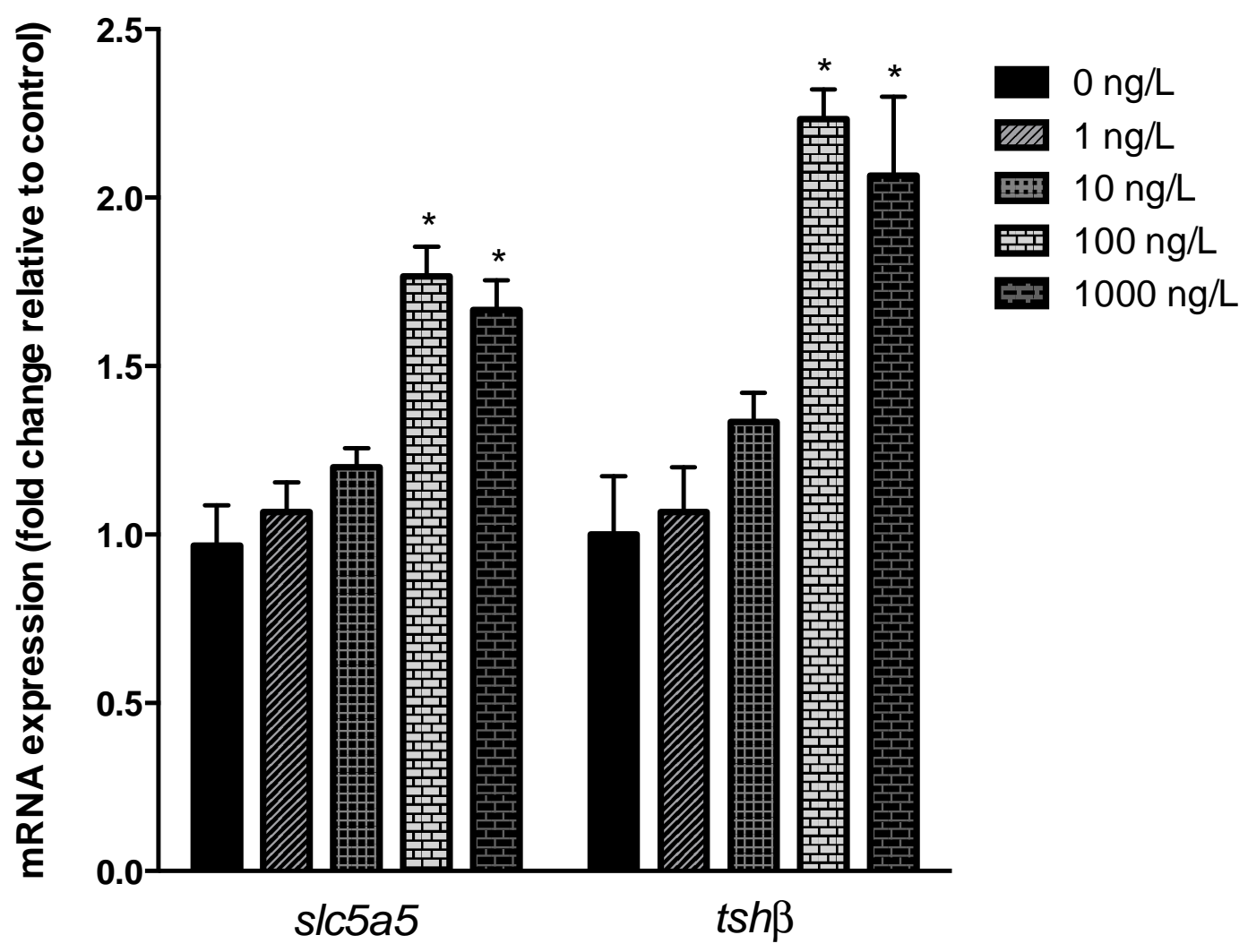




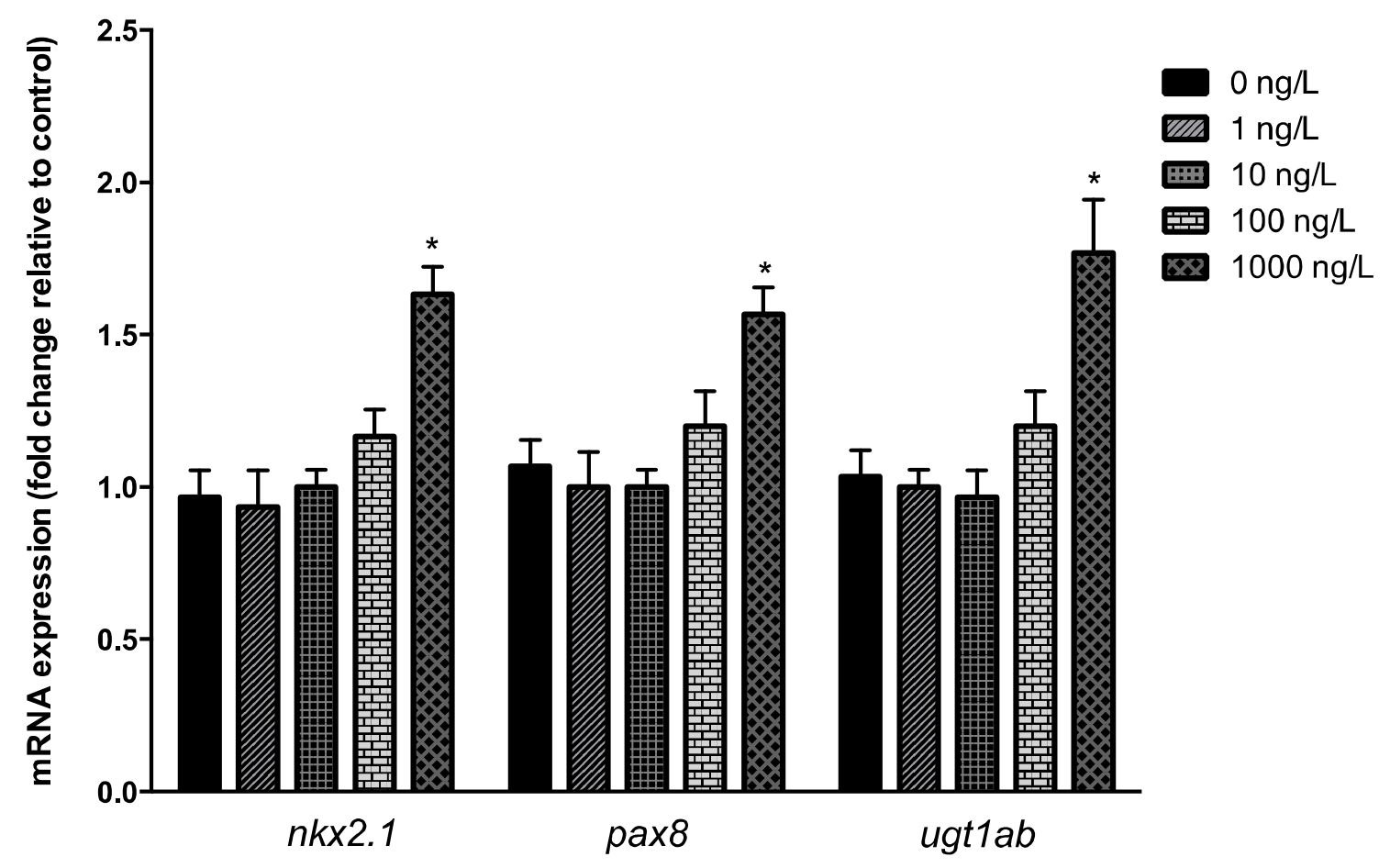

Discussion

Very little is known of the effects of progesterone on the thyroid endocrine system in fish. In this study, zebrafish embryos were used to evaluate effects of progesterone on expression of genes involved in the HPT axis. Exposure to 100 $\mathrm{ng} / \mathrm{L}$ progesterone significantly increased slc5a5 and tsh $\beta$ expression. The gene slc5a5 and tsh $\beta$ are involved in thyroid hormone synthesis pathways [37-39]. Previous studies have reported that $\operatorname{tsh} \beta$ is a useful biomarker for investigating the function of thyroid system $[40,41]$. In this study, the tsh $\beta$ mRNA expression was significantly increased when exposed to progesterone. Moreover, higher concentration of progesterone increased nkx2.1, pax8 and ugt1ab expression. Genes regulate the thyroid development (nkx2.1 and pax8) and thyroid hormone 
synthesis (slc5a5) were significantly upregulated after exposed to progesterone, these results suggested that HPT axis in the $5 \mathrm{dpf}$ zebrafish is sensitive to chemical treatment, that can be used to examine the effects of chemicals on the thyroid endocrine system.

Taken together, treatment with progesterone changed the gene expression levels involved in the HPT axis, indicating an overt endocrine-disrupting activity. This study showed that $5 \mathrm{dpf}$ zebrafish can be used to evaluate the effects of chemicals on the thyroid endocrine system.

\section{References}

1. Sumpter, J.P., Endocrine disrupters in the aquatic environment: an overview. CLEAN-Soil, Air, Water, 2005. 33(1): p. 9-16.

2. Kloas, W., et al., Endocrine disruption in aquatic vertebrates. Annals of the New York Academy of Sciences, 2009. 1163(1): p. 187-200.

3. Snyder, S.A., et al., Analytical methods for detection of selected estrogenic compounds in aqueous mixtures. Environmental Science \& Technology, 1999. 33(16): p. 2814-2820.

4. Servos, M., et al., Distribution of estrogens, $17 \beta$-estradiol and estrone, in Canadian municipal wastewater treatment plants. Science of the Total Environment, 2005. 336(1): p. 155-170.

5. Zhong, L., et al., Investigation of effect of $17 \alpha$-ethinylestradiol on vigilin expression using an isolated recombinant antibody. Aquatic toxicology, 2014. 156: p. 1-9.

6. Colborn, T., F.S. vom Saal, and A.M. Soto, Developmental effects of endocrinedisrupting chemicals in wildlife and humans. Environmental health perspectives, 1993.101(5): p. 378.

7. Nash, J.P., et al., Long-term exposure to environmental concentrations of the pharmaceutical ethynylestradiol causes reproductive failure in fish. Environmental health perspectives, 2004.112(17): p. 1725. 
8. Ankley, G.T., et al., Repeating history: pharmaceuticals in the environment. 2007, ACS Publications.

9. $\mathrm{Gu}, \mathrm{Q}$., et al., Generation and characterization of a transgenic zebrafish expressing the reverse tetracycline transactivator. Journal of genetics and genomics, 2013. 40(10): p. 523-531.

10. Sharara, F.I., D.B. Seifer, and J.A. Flaws, Environmental toxicants and female reproduction. Fertility and sterility, 1998. 70(4): p. 613-622.

11. Bretveld, R.W., et al., Pesticide exposure: the hormonal function of the female reproductive system disrupted? Reproductive Biology and Endocrinology, 2006. 4(1): p. 30.

12. Yang, X., et al., Nucleoporin 62-like protein activates canonical Wnt signaling through facilitating the nuclear import of $\beta$-catenin in zebrafish. Molecular and cellular biology, 2015. 35(7): p. 1110-1124.

13. Paulos, P., et al., Reproductive responses in fathead minnow and Japanese medaka following exposure to a synthetic progestin, Norethindrone. Aquatic Toxicology, 2010. 99(2): p. 256-262.

14. Zhu, Y., J. Bond, and P. Thomas, Identification, classification, and partial characterization of genes in humans and other vertebrates homologous to a fish membrane progestin receptor. Proceedings of the National Academy of Sciences, 2003.100(5): p. 2237-2242.

15. Dressing, G.E., et al., Membrane progesterone receptor expression in mammalian tissues: a review of regulation and physiological implications. Steroids, 2011. 76(1): p. 11-17.

16. Pellestor, F., T. Anahory, and S. Hamamah, The chromosomal analysis of human oocytes. An overview of established procedures. Human reproduction update, 2005. 11(1): p. 15-32.

17. Yamashita, Y., et al., Production of progesterone from de novo-synthesized cholesterol in cumulus cells and its physiological role during meiotic resumption of porcine oocytes. Biology of Reproduction, 2003. 68(4): p. 11931198.

18. Zhai, G., et al., Sept6 is required for ciliogenesis in Kupffer's vesicle, the pronephros, and the neural tube during early embryonic development. Molecular and cellular biology, 2014. 34(7): p. 1310-1321.

19. Lange, I.G., et al., Sex hormones originating from different livestock production systems: fate and potential disrupting activity in the environment. Analytica Chimica Acta, 2002. 473(1): p. 27-37.

20. Celiz, M.D., J. Tso, and D.S. Aga, Pharmaceutical metabolites in the environment: analytical challenges and ecological risks. Environmental Toxicology and Chemistry, 2009. 28(12): p. 2473-2484.

21. Van Der Linden, S.C., et al., Detection of multiple hormonal activities in wastewater effluents and surface water, using a panel of steroid receptor CALUX bioassays. Environmental science \& technology, 2008. 42(15): p. 5814-5820.

22. Graymore, M., F. Stagnitti, and G. Allinson, Impacts of atrazine in aquatic ecosystems. Environment international, 2001. 26(7): p. 483-495. 
23. Kolodziej, E.P. and D.L. Sedlak, Rangeland grazing as a source of steroid hormones to surface waters. Environmental science \& technology, 2007. 41(10): p. 3514-3520.

24. Corcoran, J., M.J. Winter, and C.R. Tyler, Pharmaceuticals in the aquatic environment: a critical review of the evidence for health effects in fish. Critical reviews in toxicology, 2010.40(4): p. 287-304.

25. Gu, Q., et al., Genetic ablation of solute carrier family 7a3a leads to hepatic steatosis in zebrafish during fasting. Hepatology, 2014. 60(6): p. 1929-1941.

26. Civitareale, D., et al., $A$ thyroid-specific nuclear protein essential for tissuespecific expression of the thyroglobulin promoter. The EMBO Journal, 1989. 8(9): p. 2537.

27. Stefani, G. and F.J. Slack, Small non-coding RNAs in animal development. Nature reviews Molecular cell biology, 2008. 9(3): p. 219-230.

28. Wagner, M.S., S.M. Wajner, and A.L. Maia, The role of thyroid hormone in testicular development and function. Journal of Endocrinology, 2008. 199(3): p. 351-365.

29. Seasholtz, A., R. Valverde, and R. Denver, Corticotropin-releasing hormonebinding protein: biochemistry and function from fishes to mammals. Journal of Endocrinology, 2002.175(1): p. 89-97.

30. Bianco, A.C. and B.W. Kim, Deiodinases: implications of the local control of thyroid hormone action. Journal of Clinical Investigation, 2006. 116(10): p. 2571.

31. Song, G., et al., Effective gene trapping mediated by Sleeping Beauty transposon. PloS one, 2012. 7(8): p. e44123.

32. Zoeller, R.T., S.W. Tan, and R.W. Tyl, General background on the hypothalamicpituitary-thyroid (HPT) axis. Critical reviews in toxicology, 2007. 37(1-2): p. 11-53.

33. Peter, M.S., The role of thyroid hormones in stress response of fish. General and Comparative Endocrinology, 2011.172(2): p. 198-210.

34. Chen, Q., et al., Bioconcentration and metabolism of decabromodiphenyl ether (BDE-209) result in thyroid endocrine disruption in zebrafish larvae. Aquatic toxicology, 2012.110: p. 141-148.

35. Fort, D.J., et al., The hypothalamic-pituitary-thyroid (HPT) axis in frogs and its role in frog development and reproduction. Critical reviews in toxicology, 2007. 37(1-2): p. 117-161.

36. Meng, S., et al., Transdifferentiation Requires iNOS ActivationNovelty and Significance. Circulation Research, 2016. 119(9): p. e129-e138.

37. Fetter, E., et al., Comparative analysis of goitrogenic effects of phenylthiourea and methimazole in zebrafish embryos. Reproductive Toxicology, 2015. 57: p. 10-20.

38. Yu, L., et al., Parental transfer of polybrominated diphenyl ethers (PBDEs) and thyroid endocrine disruption in zebrafish. Environmental science \& technology, 2011. 45(24): p. 10652-10659.

39. Harun-Or-Rashid, M., et al., Effect of thyroid statuses on sodium/iodide symporter (NIS) gene expression in the extrathyroidal tissues in mice. Thyroid research, 2010. 3(1): p. 3. 
40. Chan, W.K. and K.M. Chan, Disruption of the hypothalamic-pituitary-thyroid axis in zebrafish embryo-larvae following waterborne exposure to BDE-47, TBBPA and BPA. Aquatic toxicology, 2012. 108: p. 106-111.

41. Raldúa, D. and P.J. Babin, Simple, rapid zebrafish larva bioassay for assessing the potential of chemical pollutants and drugs to disrupt thyroid gland function. Environmental science \& technology, 2009.43(17): p. 6844-6850. 